\title{
Determinação da capacidade real necessária de um processo produtivo utilizando cadeia de Markov
}

\author{
Francielly Hedler Staudta*, Antonio Sérgio Coelho ${ }^{\mathrm{b}}$, \\ Mirian Buss Gonçalves ${ }^{\mathrm{c}}$ \\ a*franhedler@gmail.com, UFSC, Brasil \\ bcoelho@deps.ufsc.br, UFSC, Brasil \\ ‘mirianbuss@deps.ufsc.br, UFSC, Brasil
}

\begin{abstract}
Resumo
Todas as empresas em desenvolvimento passam pelo momento de decidir se há ou não necessidade de realizar novos investimentos para suprir uma demanda crescente. Para tomar tal decisão é imprescindível conhecer se o processo atual tem capacidade de produzir a nova demanda. Porém, são raras as empresas que têm a percepção de que os refugos e retrabalhos também consomem recursos da produção e, portanto, devem ser considerados no cálculo da capacidade produtiva. A proposta deste trabalho consiste em incluir esses fatores na análise de capacidade da fábrica, utilizando uma matriz de transição estocástica da cadeia absorvente de Markov como ferramenta para obtenção do fator de capacidade. Este fator, aliado ao índice de eficiência e a demanda desejada ao fim do processo, resulta na capacidade real necessária. Um estudo de caso exemplifica a metodologia, apresentando resultados que permitem o cálculo do índice de ocupação real de cada centro produtivo. 0 cálculo desse índice demonstrou que alguns centros de trabalho necessitam de análises sobre investimentos em capacitação, pois ultrapassaram $90 \%$ de ocupação.
\end{abstract}

Palavras-chave

Capacidade produtiva. Métodos estocásticos. Cadeia de Markov. Grau de utilização da capacidade.

\section{Introdução}

Os investimentos em capacidade produtiva de uma empresa têm dimensão estratégica pelo fato de influenciar a sua atuação no mercado. Vários métodos são utilizados para apoiar tal decisão, que vão desde análises econômicas de mercado até a decisão baseada na experiência e percepção dos gerentes.

Ensley e Carr (2006), avaliam os comportamentos e preferências de empresários que decidem sobre investimentos de risco. Eles afirmam que os gerentes podem sofrer de excesso de confiança nas suas decisões de investimento, o que os torna tendenciosos.

Katok (2003), avalia economicamente a decisão de investir utilizando programação estocástica. Para isso, o sistema atual foi modelado (sem o novo recurso produtivo) para determinar o fluxo de caixa básico. 0 mesmo foi feito para o novo sistema, incluindo o novo recurso. Se o valor da diferença entre os fluxos de caixa for maior que o valor do recurso, ele deve ser adquirido.
Apesar dos diversos métodos para realização de um investimento específico, quando a empresa está diante de um incremento da sua demanda atual, o conhecimento da capacidade produtiva torna-se essencial. Segundo Watts et al. (2009), medidas de capacidade geram um código único para as diversas habilidades produtivas da organização. Elas criam um "espaço útil" para calcular, avaliar e comparar o desempenho de várias máquinas, sistemas ou atividades. Este indicador auxilia a companhia nas decisões sobre investimentos e foi amplamente estudado por diversos autores como Salim (2001), Slack, Chambers e Johnston (2002), Kato, Takaki e Souza (2003), Peinado e Graeml (2007) e Watts et al. (2009). Como este conceito é relativamente bem difundido no meio empresarial, será utilizado como premissa para o desenvolvimento deste trabalho.

No que tange cadeias de Markov, inúmeros trabalhos utilizam as matrizes de transição, provenientes do fluxo produtivo de uma empresa, para determinar 
custos de produção, preços de venda e capacidade produtiva. Bortolotti et al. (2007) elaboraram uma gestão de custos para guardanapos de papel utilizando cadeias absorventes de Markov. As probabilidades de absorção advindas das matrizes de transição foram utilizadas para calcular o custo dos produtos. De forma similar, Branco e Coelho (2006) empregam cadeias de Markov para determinar os custos de produção do peixe fresco e o preço final de venda do filé congelado. Além disso, informam à empresa, através do resultado das matrizes de transição, quanto deve ingressar de pescado na origem do processo para obter a quantidade média esperada no final.

Dentro deste contexto, o presente artigo utiliza a teoria de cadeias absorventes de Markov para determinar a capacidade produtiva de uma companhia, incluindo na análise quanto os refugos e retrabalhos (inerentes ao processo) consomem de recursos da fábrica.

Para isso, unem-se as informações contidas na matriz de transição estocástica de Markov com o índice de eficiência para determinar a capacidade real necessária de cada centro de trabalho da empresa para atender à demanda. Posteriormente, calcula-se o índice de ocupação para avaliar a necessidade de investimento.

0 trabalho está estruturado como segue: na seção 2, são apresentados conceitos sobre capacidade produtiva e o índice de capacidade real necessária, que serão considerados na análise de investimentos. $\mathrm{Na}$ seção 3, demonstra-se como o processo estocástico pode ser utilizado para encontrar o fator de capacidade, elemento da fórmula de capacidade real necessária. $\mathrm{Na}$ seção 4, apresentam-se os passos para implantação do método proposto. Estes procedimentos são validados na seção 5 através de um estudo de caso, e, finalmente, na seção 6 , apresentam-se as conclusões e sugestões de novos trabalhos.

\section{Capacidade produtiva e capacitações futuras}

A capacidade de produção da empresa constitui o potencial produtivo de que ela dispõe (SLACK; CHAMBERS; JOHNSTON, 2002). Ela representa o volume ideal de produção de produtos/serviços que a empresa pode realizar (KATO; TAKAKI; SOUZA, 2003).

Segundo Watts et al. (2009), a medida da capacidade ajuda a identificar o grau de produção relativa vs. a utilização não produtiva. 0 modo no qual a capacidade produtiva é mensurada e relatada afeta as decisões gerenciais, assim como o desempenho econômico da empresa. 0 cálculo da capacidade produtiva pode variar dependendo da aplicação dos dados e da filosofia da instituição. De maneira geral, Salim (2001) define a capacidade produtiva realizada como a relação do valor observado e alguma medida de capacidade de escoamento, isto é, $\mathrm{U}=\mathrm{Y} / \mathrm{Y}^{*}$; onde $\mathrm{U}$ é a capacidade produtiva realizada, $\mathrm{Y}$ é a saída observada e $Y^{*}$ é a medida de capacidade de saída teórica.

Peinado e Graeml (2007), entretanto, apresentam a capacidade em 4 categorias diferentes:

- Capacidade Instalada - é a capacidade máxima de uma unidade produtiva trabalhando ininterruptamente e não considerando perdas;

- Capacidade Disponível - é a quantidade máxima que um processo pode produzir durante a jornada de trabalho disponível. Também não considera as perdas;

- Capacidade Efetiva - representa a capacidade disponível subtraindo as perdas planejadas (paradas de setup, manutenção preventiva, etc.);

- Capacidade Realizada - é obtida subtraindo da capacidade efetiva as perdas não planejadas.

Avaliando cada categoria separadamente, observa-se que a capacidade instalada é uma medida teórica que, normalmente, não é utilizada para informações práticas sobre capacidade. Ela fornece a produção (em peças) que a fábrica pode gerar trabalhando 24 horas $\times 7$ dias. Já a capacidade disponivel considera somente as horas de trabalho diárias do recurso para calcular quanto é possível produzir. Kato, Takaki e Souza (2003) demonstram o cálculo na Equação 1, utilizando o tempo padrão como base, ou seja:

Capacidade disponível $=\frac{\mathrm{CH}}{\mathrm{TP}}$

Em que $\mathrm{CH}$ é a carga horária diária de trabalho e TP é o tempo padrão de um produto. 0 tempo padrão da Equação 1 é o tempo necessário para executar uma operação de acordo com um método estabelecido, em condições determinadas, por um operador apto e treinado, possuindo uma habilidade média, trabalhando com esforço médio, durante todas as horas do serviço (TOLEDO JUNIOR, 1989 apud LEAL et al., 2005). Portanto, este elemento possui a unidade de horas/peça, sendo a capacidade disponível em peças.

Entretanto, a capacidade disponível não desconta da carga horária diária de trabalho as inúmeras paradas programadas que ocorrem. A subtração da carga horária diária de trabalho $(\mathrm{CH})$ do tempo de paradas planejadas resulta nas horas disponíveis (HD), como mostra a Equação 2. 0 cálculo da capacidade efetiva retira as paradas planejadas pelo sistema, sendo sua fórmula dada pela Equação 3:

$\mathrm{HD}=\mathrm{CH}-$ tempo de paradas planejadas

Capacidade efetiva $=\frac{\mathrm{HD}}{\mathrm{TP}}$ 
Segundo Al-Darrab (2000), as horas disponiveis são o máximo de horas trabalhadas esperadas de um centro produtivo. Contudo, este tempo reduz ao longo do período, pois, ocasionalmente, ocorrem quebra de máquinas, absenteísmo, falta de material, etc. todas aquelas coisas que causam inevitáveis atrasos. Estas paradas não planejadas são contabilizadas pelas empresas como ineficiências da produção. 0 divisor da Equação 4, horas disponíveis menos horas paradas não planejadas, resulta nas horas trabalhadas do centro produtivo. A capacidade realizada contabiliza estas paradas não planejadas e representa uma medida da quantidade realmente produzida (em peças), conforme a Equação 4.

Capacidade realizada $=$

$=\frac{\text { HD }- \text { horas paradas não planejadas }}{\mathrm{TP}}$

Porém, esta capacidade ainda é teórica, pois a quantidade programada no início do processo é a quantidade de peças desejada na saída (output). As empresas não consideram os tempos gastos com refugo e retrabalho como produtivos, entretanto as máquinas utilizam o período disponível no dia para produzi-los. Este tempo (ou peças) deve ser considerado no cálculo de ocupação da máquina.

Peinado e Graeml (2007) apresentam um índice de eficiência que representa o desempenho da produção para o trabalho programado em termos percentuais, sendo dado pela Equação 5:

$$
\text { Índice de eficiência }=\frac{\text { capacidade realizada }}{\text { capacidade efetiva }}
$$

Reescrevendo o índice de eficiência, Equação 5, a partir da substituição direta das expressões (3) e (4) anteriores e denotando esta última versão do indíce de eficiência por eficiência, vem:

Eficiência $=\frac{\text { horas trabalhadas }}{\mathrm{HD}}$

A Equação 6 será utilizada no presente artigo. Este indice demonstra o que a empresa consegue produzir a partir da programação da demanda dentro do tempo disponível. Contudo, o trabalho visa encontrar quanto a empresa precisa produzir (input) para que obtenha a demanda na saída (output). 0 output é a quantidade de peças boas que a empresa deseja obter no final do processo produtivo.

Conforme apresentado anteriormente, dentre as diversas paradas que ocorrem em um processo, as paradas planejadas constituem-se de tempo de setup, horas de exercício laboral, refeição, etc. Estas devem estar incluídas no tempo programado pelo PCP (Planejamento e Controle da Produção) dentro das horas disponíveis do dia. Lopes et al. (2003) conceituam paradas técnicas e organizacionais, sendo as primeiras relacionadas a paradas não planejadas e as últimas a planejadas. Os autores afirmam que "os tempos organizacionais devem ser considerados no cálculo da capacidade da célula, pois estão inclusos no tempo de operação". Por este motivo, os fatores que influenciam a capacidade necessária de um centro de trabalho são a eficiência, os refugos e os retrabalhos realizados durante o processo produtivo. Para encontrar a capacidade real necessária relacionou-se o índice de eficiência a um fator, denominado fator de capacidade, que contabiliza a capacidade utilizada pelas peças programadas no início do processo. Para o cálculo deste fator, é utilizado o modelo estocástico da cadeia de Markov, que, através da sua matriz de transição, traz a quantidade utilizada do recurso para produzir uma peça. Este valor considera os refugos e retrabalhos e, consequentemente, faz aumentar a capacidade necessária para atingir a demanda. Desta forma, a Equação 7 apresenta a relação entre eficiência, fator de capacidade e demanda para obter a capacidade real necessária de um centro produtivo.

$$
\mathrm{CRN}=\frac{\mathrm{FC}}{\text { eficiência }} \times \text { DEMANDA }
$$

Em que CRN é capacidade real necessária (peças), FC é o fator de capacidade (adimensional), DEMANDA é a quantidade de peças requeridas pelo cliente (peças) e Eficiência é o índice calculado pela expressão (6) (percentual).

A partir do momento que se tem a capacidade real de cada processo, é possível calcular o percentual de ocupação do centro de trabalho (tópico abordado no estudo de caso) e determinar se há a necessidade ou não de investimentos para aumentar a capacidade. $\mathrm{Na}$ próxima seção, será apresentada a teoria de cadeia de Markov, utilizada para calcular o fator de capacidade.

\section{Processo estocástico}

Considera-se como sendo um processo estocástico, situações influenciadas por efeitos aleatórios em que se realizam observações durante um período de tempo. Estes eventos formam um conjunto de variáveis aleatórias sob um espaço amostral relacionado a uma variável de tempo $X(t)$. Os valores que $X(t)$ pode assumir são chamados de estados e o seu conjunto $X$, de espaço de estados (CLARKE; DISNEY, 1979).

Um processo de Markov é um processo estocástico em que as distribuições de probabilidade para o seu desenvolvimento futuro dependem somente do estado presente, não levando em consideração como o processo chegou a tal estado (BORTOLOTT1 et al., 2007). Segundo Clarke e Disney (1979), o sistema não possui "memória”, caso a probabilidade $(P r)$ de ocorrer um estado $i_{n}$ dependa apenas do estado $i_{n-1}$, conforme demonstra a expressão (8): 


$$
\begin{aligned}
& \operatorname{Pr}\left[X_{n}=i_{n} \mid X_{1}=i_{1} ; \ldots ; X_{n-1}=i_{n-1}\right]= \\
& =\operatorname{Pr}\left[X_{n}=i_{n} \mid X_{n-1}=i_{n-1}\right]
\end{aligned}
$$

De acordo com Papoulis (1965), uma sequência de Markov é chamada homogênea se a probabilidade condicional da Equação 9 for independente de $n$.

$$
p\left(j_{n} / i_{n-1}\right)=p_{i j}
$$

Uma cadeia de Markov é dita estacionária se for homogênea e todas as variáveis aleatórias possuírem a mesma probabilidade (PAPOULIS, 1965). Adota-se a notação $p_{i j}$ para representar a probabilidade de ocorrência da transição do estado $i$ para o estado $j$ em um período e $p_{j i}$ para o caminho inverso.

Conforme Shamblin e Stevens (1979), para garantir que se chegou a condições de regime estacionário, a cadeia deve ser ergódica. Uma cadeia ergódica descreve matematicamente um processo no qual é possível ir de um estado a qualquer outro. Não é necessário que isto seja feito em apenas um passo, mas deve ser possível atingir qualquer estado independentemente do presente.

Os pontos mais importantes na montagem de uma cadeia de Markov são a definição dos estados do sistema e a construção da matriz de transição probabilística (HOYOS, 1980).

Na Figura 1, apresenta-se um exemplo de cadeia produtiva com as respectivas probabilidades de transição. Os estados são Produção 1, Produção 2, Inspeção, Expedição e Refugo.

A partir do fluxo produtivo apresentado, a matriz de transição é formada. Segundo Branco e Coelho (2006), estas matrizes, denominadas $P$, são estocásticas, pois cada linha que as compõe é uma distribuição (soma das probabilidades é igual a 1).

No diagrama da matriz $P$, cada linha $i$ representa o estado atual e cada coluna $j$ representa o estado futuro (a ordem dos estados atuais deve ser igual à dos estados futuros, respectivamente, nas linhas e nas colunas de $P$ ). Segundo Shamblin e Stevens (1979), $P$ dá as probabilidades de se estar em determinado estado para todas as condições ou estados iniciais possíveis. $\mathrm{Na}$ Figura 2, apresenta-se a matriz de transição estocástica do processo produtivo representado na Figura 1.

A matriz pode ser exibida na forma de quatro submatrizes, conforme Figura 3.

Cada submatriz significa, respectivamente:

- $\mathrm{N}$ - matriz que representa as probabilidades de transição entre um estado não absorvente para outro não absorvente;

- A - matriz com as probabilidades de transição de um estado não absorvente passar a ser absorvente;

- 0 - matriz nula, representando as probabilidades de transição de sair de um estado absorvente para um não absorvente;
- 1 - matriz identidade, representando a probabilidade de transição de se permanecer dentro de um estado absorvente.

Então, para o exemplo citado na Figura 1, os estados absorventes são Expedição e Refugo.

Segundo Alves e Delgado (1997), decorrido um número muito elevado de períodos de tempo $(n \rightarrow \infty)$, a probabilidade de o processo estar no estado $j$ é constante e independente do estado inicial $i$, ou seja, os elementos da matriz $(\mathbf{1}-N)^{-1} A$ são as probabilidades estacionárias de absorção.

Terra (2006) descreve que o número esperado de períodos até o estado ser absorvido, ou seja, até alcançar algum estado absorvente, é o i-ésimo elemento da matriz $(1-N)^{-1 *} e$, em que "e" é um vetor com todos os seus elementos iguais a 1 . Portanto, a matriz $(1-N)^{-1}$ dá o número esperado de vezes em que o processo está em cada estado não absorvente antes da absorção (SHAMBLIN; STEVENS, 1979).

Conclui-se que as células da matriz fundamental $(1-M)^{-1}$ informam quantas vezes uma peça passou por cada estágio até ser absorvido, o que permite calcular a capacidade necessária em cada centro de trabalho para a produção de uma peça.

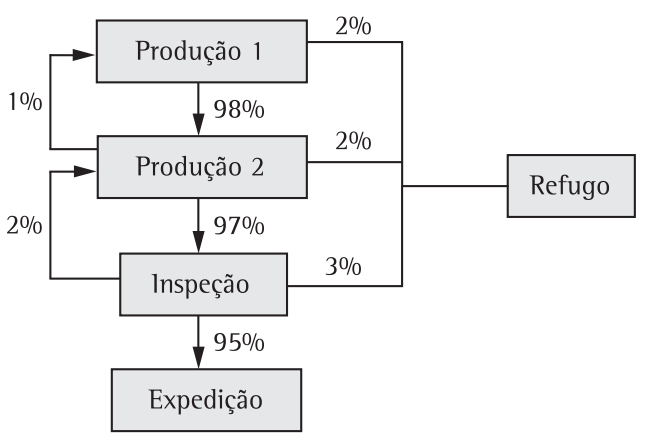

\begin{tabular}{|c|c|c|c|c|c|c|}
\hline & P1 & P2 & 11 & Exp & $\mathrm{R}$ & \\
\hline & 0 & 0,98 & 0 & 0 & 0,02 & P1 \\
\hline & 0,01 & 0 & 0,97 & 0 & 0,02 & P2 \\
\hline & 0 & 0,02 & 0 & 0,95 & 0,03 & 11 \\
\hline & 0 & 0 & 0 & 1 & 0 & $\operatorname{Exp}$ \\
\hline & 0 & 0 & 0 & 0 & 1 & $\mathrm{R}$ \\
\hline
\end{tabular}

Figura 1. Fluxo produtivo com probabilidades de transição. Fonte: Elaborada pelos autores.

Figura 2. Matriz de transição estocástica do processo produtivo exemplificado. Fonte: Elaborada pelos autores.

$$
P=\left[\begin{array}{c:c}
N & A \\
\hdashline 0 & 1
\end{array}\right]
$$

Figura 3. Matriz de transição estocástica constituída por submatrizes. 
Para este trabalho, será utilizado o resultado da matriz para identificar os fatores de capacidade (elemento da Equação 7). Na seção 4, será apresentada a metodologia para implantação da teoria aqui exposta, seguida de um estudo de caso como aplicação prática.

\section{Metodologia}

0 trabalho propõe demonstrar que os refugos e retrabalhos produzidos em uma empresa devem ser incluídos no cálculo da capacidade de cada centro de trabalho. Partindo do pressuposto de que as ineficiências consomem recursos produtivos, necessita-se conhecer a capacidade necessária para obter a demanda do cliente no final do processo. Esta capacidade real necessária (CRN) - apresentada na Equação 7 - é calculada a partir da eficiência do centro de trabalho agregada a um fator de capacidade (FC). Quando a capacidade real necessária (CRN) é comparada à capacidade atual considerada pela empresa, gera-se um percentual de incremento que revela a diferença entre a situação ponderada e a necessária. Posteriormente, avalia-se a condição da empresa através do percentual de ocupação. Este índice demonstra a carga de trabalho da célula de produção em relação à disponibilidade de fabricação. A Figura 4 resume as etapas para a implantação da metodologia.

Na próxima seção apresenta-se o estudo de caso que demonstra a aplicação da metodologia abordada.

\section{Estudo de caso}

0 estudo de caso foi realizado em uma empresa fabricante de motores elétricos renomada na América Latina. Considerando a situação da empresa estável em relação à demanda, treinamento de pessoal e tipos de máquinas a serem utilizadas, obteve-se da empresa os valores de refugo e retrabalho de cada centro de trabalho pelo período de dois meses (outubro e novembro de 2008). Cabe ressaltar que a empresa investe muitos esforços na melhoria contínua da qualidade. Os dados de refugo e de retrabalho podem, então, ser considerados estáveis, visto que todo o processo de minimização já foi e continua sendo realizado. Assume-se, portanto, que as propriedades da cadeia de Markov dadas pelas Equações 8 e 9 são verificadas para o estudo de caso. Quando qualquer parâmetro de produção, quantidade de máquinas e treinamento sofrer alterações, todo o levantamento estatístico deve ser reavaliado.

Os componentes do produto final são muito variados (ventilador, estator, cobre, cabo, etc.), o que gerou diversas unidades de medida para representar as perdas e retrabalhos (kg, peças, metro, etc.). A unidade padrão utilizada no trabalho são peças (motor final). Por esse motivo, dentro do mix de produção, fez-se uma média dos insumos utilizados por todos os tipos de motores para realizar a transformação da unidade.

Posteriormente, realizou-se um levantamento das etapas do processo produtivo (Figura 5) conforme 0 exemplo demonstrado na Figura 1. As probabilidades de transição foram fornecidas pela empresa, que, através de um histórico de pedidos (demanda da fábrica), conhece os percentuais da produção que passa em cada centro de trabalho. De maneira geral, as peculiaridades de cada produto determinam as células produtivas utilizadas para sua fabricação. Apresenta-se na Figura 5, um fluxograma dos processos existentes no departamento de fabricação da empresa, demonstrando o mix de produção que passa em cada centro de trabalho a partir da demanda inicial programada (100\%).
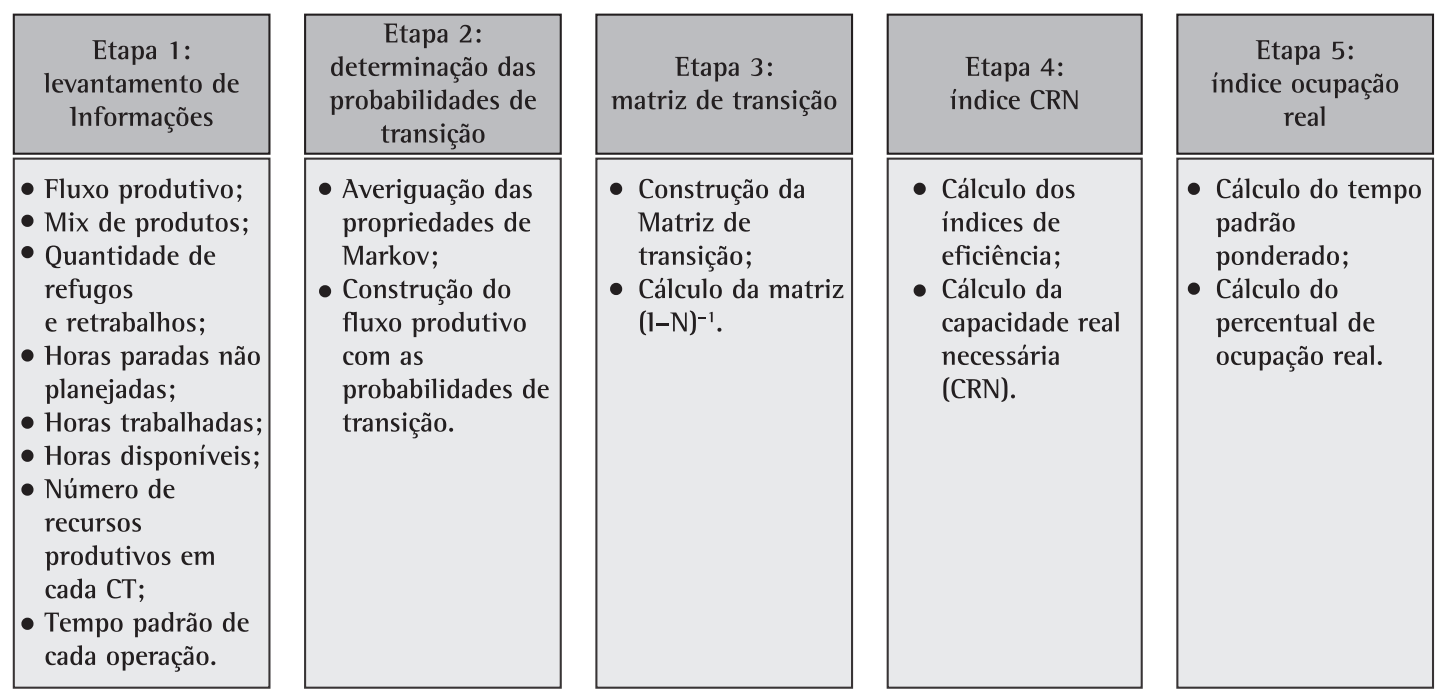

Figura 4. Etapas da metodologia de trabalho. Fonte: Elaborada pelos autores. 


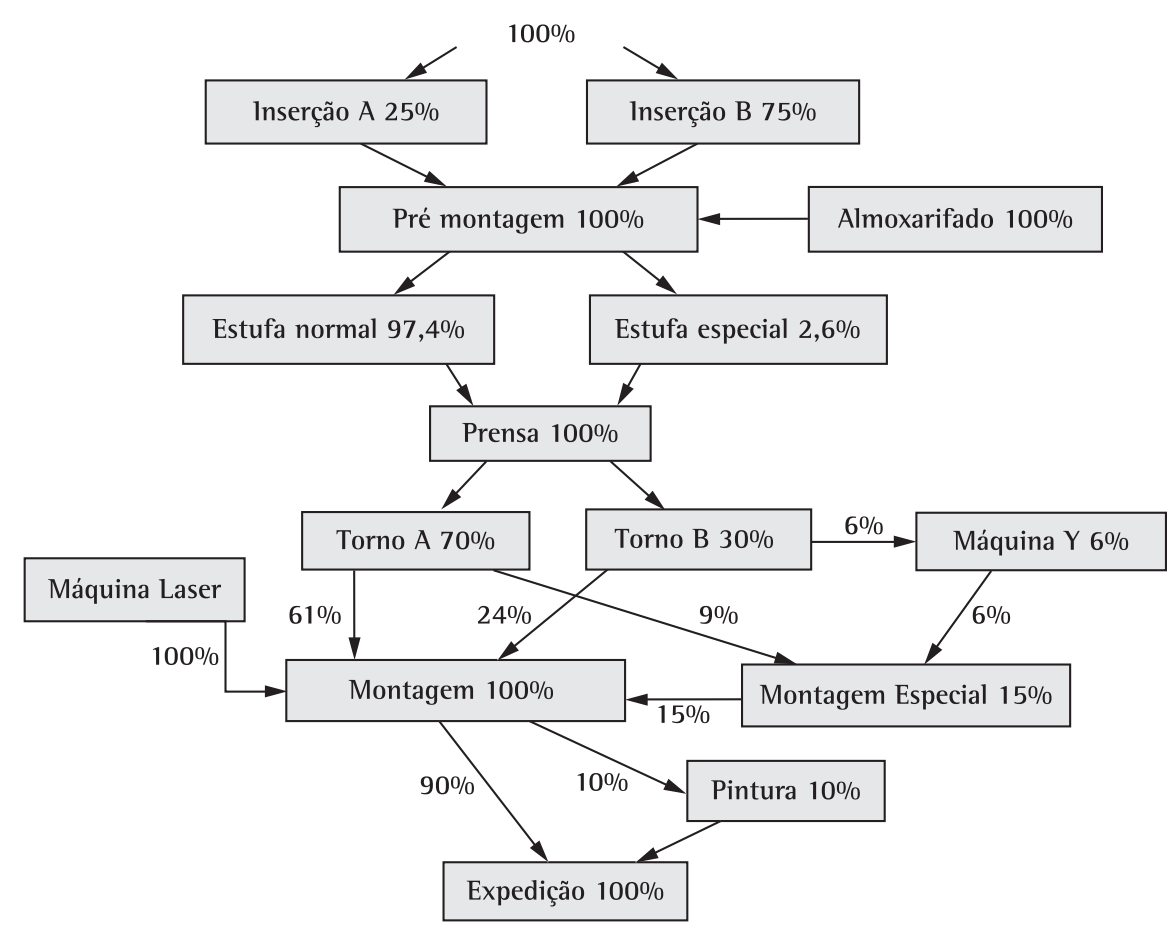

Figura 5. Fluxograma demonstrando o mix de produção. Fonte: Elaborada pelos autores.

A demanda percebida no início do processo é aleatória, devido aos pedidos dos clientes, todavia, as probabilidades durante o processo não se alteram. As porcentagens significam, por exemplo, que, de todos os produtos que passam na prensa, historicamente $70 \%$ vão para o torno $A$, devido aos seus requisitos, e os outros 30\% vão para o torno B.

Os centros de trabalho almoxarifado e máquina laser abastecem a pré-montagem e a montagem, respectivamente, com componentes necessários para a execução das peças que os centros fabricam.

Dentro do fluxo de produtos da fábrica, existem as peças boas e os refugos e retrabalhos. As peças boas passam pelo centro produtivo uma única vez, enquanto o refugo insere um novo processamento da peça desde o início da cadeia, podendo ocorrer em qualquer um dos centros de trabalho. Já com o retrabalho, duas situações podem ocorrer: a carga de trabalho de outros centros pode ser influenciada, dependendo do tipo de falha cometida, ou pode implicar somente aumento da carga no próprio local. Como a empresa não identifica nos apontamentos de retrabalho se a peça foi para outro centro ou não, foi descartada a hipótese da peça ser retrabalhada em outras células de trabalho. Em situações de retrabalho no chão de fábrica, as peças entram no lote seguinte para serem processadas normalmente. Por este motivo, no artigo, as peças reprocessadas são tratadas pela empresa como peças normais, e as chances de ela ser classificada para refugo e retrabalho (no segundo processamento) são iguais às de qualquer outra peça nova.
Resumidamente, serão contempladas as seguintes situações:

- os refugos são identificados e excluídos no centro de trabalho em que a peça está sendo processada;

- os retrabalhos são identificados e realizados no próprio local. Não serão consideradas transferências de peças para tal finalidade entre os centros de trabalho;

- quando o retrabalho ocorre, ele reutiliza 100\% do processo, ou seja, a peça é totalmente reprocessada.

A Figura 6 apresenta novamente o fluxo produtivo, porém, agora, com a inclusão dos refugos e retrabalhos de cada parte do processo. Estes reduzem a quantidade de peças boas que vão para o próximo estado, visto que os refugos são peças eliminadas do fluxo e os retrabalhos aumentam a carga do centro por produzirem duas vezes a mesma peça.

A demanda inicial programada é 100\% da produção da fábrica. Cada centro de trabalho é responsável por um percentual desta produção. Na Figura 6, considerou-se que este percentual equivale a 100\% do que é fabricado nesta célula de trabalho. A partir do total que entra para ser fabricado, o destino pode ser refugo, retrabalho ou próximo processo. Como os centros de trabalho recebem as peças boas das etapas anteriores, a soma delas pode resultar em um valor maior que $100 \%$.

0 Lote 100\% não significa um centro de trabalho, mas sim um total de peças do estoque que compõe a produção do dia. Ele foi incluído no fluxograma para que, ao se construir a matriz de transição, os centros 


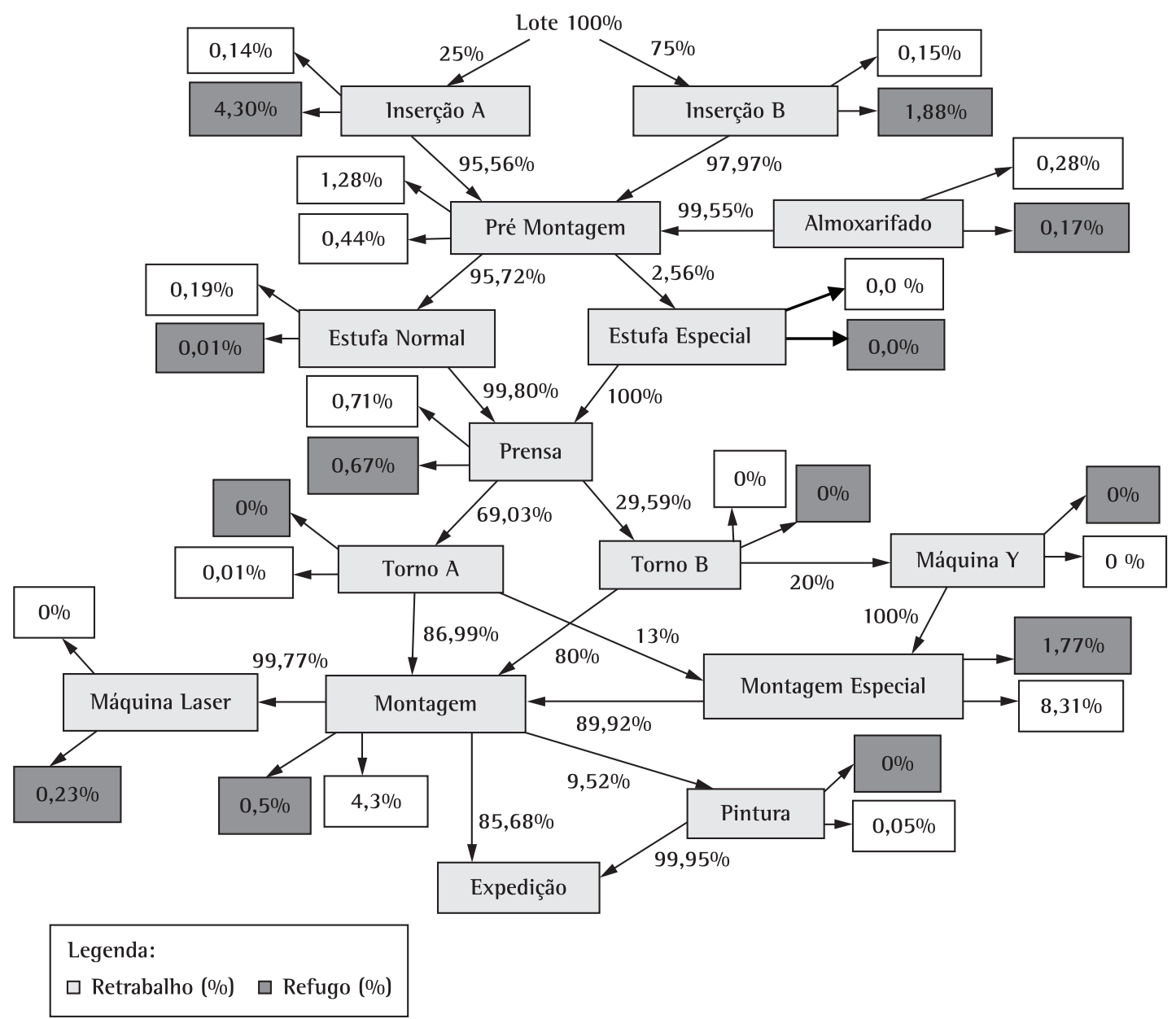

Figura 6. Fluxograma com porcentagens de refugo e retrabalho em cada CT. Fonte: Elaborada pelos autores.

de trabalho inserção manual e mecanizada tivessem seus valores de capacidade calculados.

A Tabela 1 demonstra a matriz de transição estocástica que foi representada no fluxograma da Figura $6 \mathrm{com}$ as respectivas probabilidades entre centros de trabalho. Os estados absorventes são o refugo e expedição e todos os outros são classificados como não absorventes.

A única exceção é o retrabalho, que não é um estado, mas sim a probabilidade de transição do centro para ele mesmo (por exemplo, as células $\mathrm{a}_{22}, \mathrm{a}_{33}, \mathrm{a}_{44}$, etc.).

A partir da Tabela 1, calculou-se $\left(1-M^{-1}\right.$ que está apresentado na Tabela 2. Segundo Shamblin e Stevens (1979), a primeira linha da matriz $\left(1-M^{-1}\right.$ fornece valores que representam o número esperado de tempo gasto em cada centro de operação por uma peça que entra. Portanto, a primeira linha demonstra os fatores de capacidade da fórmula de capacidade real necessária, pois é a quantidade de recursos necessários para fazer uma peça.

Porém, para a capacidade do almoxarifado e máquina laser, aparecem zeros na primeira linha da matriz
(Tabela 2). Isto ocorreu por serem processos que têm entrada independente do fluxo principal e não estão ligados diretamente ao início do sistema produtivo.

Para Terra (2006), os valores da matriz de transição $\left(1-M^{-1}\right.$ significam o número de períodos gastos pelo recurso até ele ir para o próximo estágio. Partindo deste pressuposto, todas as células da matriz possuem a mesma propriedade. 0 valor da célula que relaciona o almoxarifado com ele mesmo corresponde à necessidade de mais capacidade por causa do retrabalho do centro produtivo. Os valores da primeira linha levam em consideração a quantidade de peças que vão fluindo ao longo do processo e os refugos reduzem a necessidade de capacidade. Todavia, o retrabalho a faz aumentar. Como o almoxarifado e a máquina laser são "independentes" do processo, ou seja, o retrabalho que ocorre ao longo do fluxo não influencia diretamente seus valores de capacidade, as células destacadas na Tabela 2 estão representando parcialmente este fator. Portanto, a capacidade do almoxarifado e da máquina laser não pode estar baseada em 100\% da produção programada, pois 
Tabela 1. Matriz de transição estocástica (valores estão em \%).

\begin{tabular}{|c|c|c|c|c|c|c|c|c|c|c|c|c|c|c|c|c|c|}
\hline & Lote & $\operatorname{lns} A$ & Ins B & $\begin{array}{c}\text { Pré } \\
\text { mont. }\end{array}$ & Almox. & $\begin{array}{c}\text { Estufa } \\
\text { normal }\end{array}$ & $\begin{array}{l}\text { Estufa } \\
\text { esp. }\end{array}$ & Prensa & $\begin{array}{c}\text { Torno } \\
\text { A }\end{array}$ & $\begin{array}{c}\text { Torno } \\
\text { B }\end{array}$ & $\begin{array}{c}\text { Máq. } \\
Y\end{array}$ & $\begin{array}{l}\text { Mont. } \\
\text { esp. }\end{array}$ & Mont. & Laser & Pint. & Exped. & Refugo \\
\hline & 0,00 & 25,00 & 75,00 & & & & & & & & & & & & & & 0,00 \\
\hline Inserção A & 0,00 & 0,15 & 0,00 & 95,56 & 0,00 & 0,00 & 0,00 & 0,00 & 0,00 & 0,00 & 0,00 & 0,00 & 0,00 & 0,00 & 0,00 & 0,00 & 4,30 \\
\hline Inserção B & 0,00 & 0,00 & 0,15 & 97,97 & & 0,00 & 0,00 & 0,00 & 0,00 & 0,00 & 0,00 & 0,00 & 0,00 & 0,00 & 0,00 & 0,00 & 1,88 \\
\hline Pré montagem & 0,00 & 0,00 & 0,00 & 1,28 & & 95,72 & 2,56 & 0,00 & 0,00 & 0,00 & 0,00 & 0,00 & 0,00 & 0,00 & 0,00 & 0,00 & 0,44 \\
\hline Almoxar & 0,00 & & 0,00 & 99,55 & & 0,00 & 0,00 & & 0,00 & 0,00 & 0,00 & 0,00 & & 0,00 & 0,00 & 0,00 & 0,17 \\
\hline Estufa normal & 0,00 & 0,00 & 0,00 & 0,00 & 0,00 & 0,19 & 0,00 & 99,8 & 0,00 & 0,00 & 0,00 & 0,00 & 0,00 & 0,00 & 0,00 & 0,00 & 0,01 \\
\hline Estufa especial & 0,00 & 0,00 & 0,00 & 0,00 & 0,00 & 0,00 & 0,00 & 100 & 0,00 & 0,00 & 0,00 & 0,00 & 0,00 & 0,00 & 0,00 & 0,00 & 0,00 \\
\hline & 0,00 & & & 0,00 & & & & & 69,03 & 29,58 & 0,00 & 0,00 & 0,00 & 0,00 & 0,00 & 0,00 & 0,67 \\
\hline Torno A & 0,00 & & & 0,00 & & 0,00 & 0,00 & & 0,01 & 0,00 & 0,00 & 13,00 & & 0,00 & 0,00 & 0,00 & 0,00 \\
\hline Torno B & 0,00 & 0,00 & 0,00 & 0,00 & 0,00 & 0,00 & 0,00 & 0,00 & 0,00 & 0,01 & 20,00 & 0,00 & 79,99 & 0,00 & 0,00 & 0,00 & 0,01 \\
\hline Máquina Y & 0,00 & 0,00 & 0,00 & 0,00 & & 0,00 & 0,00 & & 0,00 & 0,00 & 0,00 & 100,00 & 0,00 & 0,00 & 0,00 & 0,00 & 0,00 \\
\hline Mont & 0,00 & 0,00 & 0,00 & 0,00 & & 0,00 & 0,00 & 0,00 & 0,00 & 0,00 & 0,00 & 8,31 & 89,92 & 0,00 & 0,00 & 0,00 & 1,77 \\
\hline & 0,00 & 0,00 & 0,00 & 0,00 & & 0,00 & 0,00 & 0,00 & 0,00 & 0,00 & 0,00 & 0,00 & 4,28 & 0,00 & 9,52 & 85,68 & 0,51 \\
\hline Máq. laser & 0,00 & 0,00 & 0,00 & 0,00 & 0,00 & 0,00 & 0,00 & 0,00 & 0,00 & 0,00 & 0,00 & 0,00 & 99,78 & 0,00 & 0,00 & 0,00 & 0,22 \\
\hline Pintura & 0,00 & 0,00 & 0,00 & 0,00 & & 0,00 & 0,00 & 0,00 & 0,00 & 0,00 & 0,00 & 0,00 & 0,00 & 0,00 & 0,05 & 99,95 & 0,00 \\
\hline Expedição & 0,00 & 0,00 & 0,00 & 0,00 & 0,00 & 0,00 & 0,00 & 0,00 & 0,00 & 0,00 & 0,00 & 0,00 & 0,00 & 0,00 & 0,00 & 100 & 0,00 \\
\hline Refugo & 0,00 & 0,00 & 0,00 & 0,00 & 0,00 & 0,00 & 0,00 & 0,00 & 0,00 & 0,00 & 0,00 & 0,00 & 0,00 & 0,00 & 0,00 & 0,00 & 100,00 \\
\hline
\end{tabular}

Tabela 2. Resultado da matriz $\left(1-M^{-1}\right.$.

\begin{tabular}{|c|c|c|c|c|c|c|c|c|c|c|c|c|c|c|c|}
\hline & Lote & $\operatorname{lns} A$ & lns B & $\begin{array}{c}\text { Pré } \\
\text { mont. }\end{array}$ & Almox. & $\begin{array}{c}\text { Estufa } \\
\text { normal }\end{array}$ & $\begin{array}{c}\text { Estufa } \\
\text { esp. }\end{array}$ & Prensa & $\begin{array}{c}\text { Torno } \\
\text { A }\end{array}$ & $\begin{array}{c}\text { Torno } \\
\text { B }\end{array}$ & $\begin{array}{c}\text { Máq. } \\
\text { Y }\end{array}$ & $\begin{array}{c}\text { Mont. } \\
\text { esp }\end{array}$ & Mont. & Laser & Pint. \\
\hline Lote & & & & & & & & & & & 0,058 & & & & \\
\hline Inserção A & 000 & 1,001 & 0,000 & 0,969 & 0,000 & 930 & חمחم & 0,959 & 0,662 & 0,284 & 0,057 & 0,156 & 0,986 & 0,000 & 0,094 \\
\hline Inserção B & 0,000 & 0,000 & 1,002 & 0,994 & 0,000 & 0,953 & 0,000 & 0,984 & 0,679 & 0,291 & 0,058 & 0,160 & 1,011 & 0,000 & 0,096 \\
\hline Pré Montagem & 0,000 & 0,000 & 0,000 & 1,013 & 0,000 & 0,972 & 0,026 & 1,003 & 0,692 & 0,297 & 0,059 & 0,163 & 1,030 & 0,000 & 0,098 \\
\hline Almoxarifado & 0,000 & 0,000 & 0,000 & 1,011 & 1,003 & 0,970 & 0,026 & 1,000 & 0,691 & 0,296 & 0,059 & 0,163 & 1,028 & 0,000 & 0,098 \\
\hline Estufa Normal & 0,000 & 0,000 & 0,000 & 0,000 & 0,000 & 1,002 & 0,000 & 1,007 & 0,695 & 0,298 & 0,060 & 0,164 & 1,035 & 0,000 & 0,099 \\
\hline Estufa Especial & 0,000 & 0,000 & 0,000 & 0,000 & 0,000 & 0,000 & 1,000 & 1,007 & 0,695 & 0,298 & 0,060 & 0,164 & 1,035 & 0,000 & 0,099 \\
\hline Prensa & 0,000 & 0,000 & 0,000 & 0,000 & 0,000 & 0,000 & 0,000 & 1,007 & 0,695 & 0,298 & 0,060 & & 1,035 & 0,000 & 0,099 \\
\hline Torno A & 0,000 & 0,000 & 0,000 & 0,000 & 0,000 & 0,000 & 0,000 & 0,000 & 1,000 & 0,000 & 0,000 & 0,142 & 1,042 & 0,000 & 0,099 \\
\hline Torno B & 0,000 & 0,000 & 0,000 & 0,000 & 0,000 & 0,000 & 0,000 & 0,000 & 0,000 & 1,000 & 0,200 & 0,218 & 1,041 & 0,000 & 0,099 \\
\hline Máquina Y & 0,000 & 0,000 & 0,000 & 0,000 & 0,000 & & 0,000 & 0,000 & 0,000 & 0,000 & 1,000 & 1,091 & 1,025 & 0,000 & 0,098 \\
\hline Mont Especial & 0,000 & 0,000 & 0,000 & 0,000 & 0,000 & & 0,000 & 0,000 & 0,000 & 0,000 & 0,000 & 1,091 & 1,025 & 0,000 & 0,098 \\
\hline Montagem & 0,000 & 0,000 & 0,000 & 0,000 & 0,000 & 0,000 & 0,000 & 0,000 & 0,000 & 0,000 & 0,000 & 0,000 & 1,045 & 0,000 & 0,100 \\
\hline Máquina Laser & 0,000 & 0,000 & 0,000 & 0,000 & 0,000 & 0,000 & 0,000 & 0,000 & 0,000 & 0,000 & 0,000 & 0,000 & 1,042 & 1,000 & 0,099 \\
\hline Pintura & 0,000 & 0,000 & 0,000 & 0,000 & 0,000 & 0,000 & 0,000 & 0,000 & 0,000 & 0,000 & 0,000 & 0,000 & 0,000 & 0,000 & 1,001 \\
\hline
\end{tabular}

as perdas reduzem a quantidade de peças que vão para o próximo centro de trabalho. Por este motivo precisa-se determinar a quantidade de peças que entram para produção, para então calcular o fator de capacidade. Para o almoxarifado, a quantidade de peças que chegam à Pré-Montagem para serem produzidas é apresentada na Equação 10 pela multiplicação das probabilidades de transição dos centros de trabalho que estão apresentados na Figura 6, que são:

$\mathrm{QPM}=\left(\mathrm{PE} \_\right.$Ins $\mathrm{A} \times \mathrm{PS} \_$Ins $\left.\mathrm{A}\right)+\left(\mathrm{PE} \_\right.$InsB $\times$PS_InsB $)$

Os elementos da Equação 10 representam: QPM é a quantidade de peças que chegam na pré-montagem, PE_InsA é o percentual de produtos que entram no centro inserção A, PS_lnsA é o percentual de produtos que saem do centro inserção $A, P E \_l n s B$ é o percentual de produtos que entram no centro inserção B e PS_InsB é o percentual de produtos que saem do centro inserção B. A Equação 11 demonstra os valores de cada elemento da Equação 10:

$\mathrm{QPM}=(0,25 \times 0,9556)+(0,75 \times 0,9797)=97,37 \% \quad(11)$

Contudo a quantidade de peças boas que sai do almoxarifado não é a mesma que entra em função dos refugos do próprio centro de trabalho. Para solucionar esta questão, a Equação 12 apresenta o fator de capacidade do almoxarifado. Somou-se o percentual de retrabalho à quantidade de peças boas (QPB) porque ele já está sendo considerado na célula $A_{55}$.

$$
\begin{aligned}
& \text { FC almox }=\frac{Q P M \times \text { célula } A_{55}}{\text { QPB almox }+ \text { retrabalho almox }}= \\
& =\frac{0,9737 \times 1,003}{0,9955+0,0028}=0,978
\end{aligned}
$$


O QPB significa a quantidade de peças boas e o FC é o fator de capacidade. Os valores da QPM, QPB Almox e Retrabalho Almox provêm do fluxograma da Figura 6.

Para encontrar o percentual de peças que chegam ao centro de trabalho da Montagem, calculou-se a matriz $\left(1-M^{-1} A\right.$. Os seus valores demonstram o percentual de peças que chegam à expedição, dado que uma peça entrou no sistema. A Tabela 3 apresenta o resultado, sendo que os valores da primeira linha significam que, de $100 \%$ de peças que entram no processo, 95,6\% saem na expedição e os outros 4,4\% vão para refugo. Portanto, somando os refugos dos processos anteriores à quantidade de peças que saem na expedição, encontra-se o percentual de peças que chegam à montagem (Equação 13). Os valores foram retirados do fluxo da Figura 6.

PM = PExpedição + PRef Pintura +

+ PRef Montagem $=0,956+0+0,005=96,1 \%$

Os elementos da Equação 13 significam: PM é o percentual de peças que chegam à montagem, PExpedição é o percentual de peças que chegam à Expedição (Tabela 3) e PRef é o percentual de refugo.

Utilizando a Equação 12 para os dados da máquina laser, tem-se:

$$
\begin{aligned}
& \text { FC Máq Laser }=\frac{\mathrm{PM} \times \text { célulaA } \mathrm{A}_{1414}}{\mathrm{QPB} \text { Laser }+ \text { RetrabalhoLaser }}= \\
& =\frac{0,961 \times 1}{0,9977+0}=0,963
\end{aligned}
$$

Depois dos fatores de capacidade, os índices de eficiência foram calculados conforme a Equação 6, utilizando as informações de horas trabalhadas fornecidas pela empresa. A carga horária disponível é de 8,8 horas (já foi retirado o tempo de refeição) e paradas de setup e manutenção preventiva são programadas pelo PCP.

Tabela 3. Resultado da matriz $\left(1-M^{-1} \mathrm{~A}\right.$.

\begin{tabular}{ccc} 
& Exp & Refugo \\
\hline Lote & 0,956 & 0,044 \\
Inserção A & 0,938 & 0,062 \\
Inserção B & 0,962 & 0,038 \\
Pré-montagem & 0,981 & 0,019 \\
Almoxarifado & 0,979 & 0,021 \\
Estufa normal & 0,985 & 0,015 \\
Estufa especial & 0,985 & 0,015 \\
Prensa & 0,985 & 0,015 \\
Torno A & 0,992 & 0,008 \\
Torno B & 0,991 & 0,009 \\
Máquina Y & 0,975 & 0,025 \\
Montagem especial & 0,975 & 0,025 \\
Montagem & 0,994 & 0,006 \\
Máquina laser & 0,992 & 0,008 \\
Pintura & 1 & 0 \\
\hline
\end{tabular}

A capacidade real necessária indica quanto o centro produtivo precisa ter de recursos para obter a demanda real no final do processo. De acordo com a Equação 7, o fator de capacidade multiplica o valor da demanda final da fábrica (1000 pçs) que é dividido pela eficiência do centro de trabalho (Equação 6). Para que se possa comparar a capacidade atual que a empresa considerava necessária $(A)$ e o novo índice de capacidade real necessária (B), apresenta-se na Tabela 4 o percentual de incremento de capacidade para cada centro.

Na Tabela 4, o percentual de incremento demonstra que a capacidade de cada centro produtivo deve ser maior do que a demanda do mercado devido a suas ineficiências. Caso ocorra um aumento da demanda da fábrica, altera-se somente a quantidade na coluna demanda, visto que o fator capacidade só muda caso as probabilidades de transição entre os centros de trabalho e a quantidade de refugos e retrabalhos deixem de ser estáveis. Neste caso, todos os passos precisam ser refeitos.

Entretanto, este valor da capacidade real necessária não avalia a necessidade de novos investimentos para atender a um aumento de demanda. Para isso, será necessário avaliar o percentual de ocupação de cada centro de trabalho, que é definido pela Equação 15:

Ocupação real $=\frac{\mathrm{TPM} \times \mathrm{D}}{\mathrm{HD} \times \mathrm{NR}} \times \%$ lncremento

Em que TPM é o tempo padrão médio, $D$ é a demanda, HD são as horas disponíveis e NR é o número de recursos. 0 tempo padrão médio provém do cálculo da média ponderada de peças por hora dentro do mix produtivo. A demanda é a quantidade desejada de produtos no final do processo. 0 número de recursos é a quantidade de máquinas ou postos de trabalho que executam a mesma tarefa. 0 percentual de incremento, obtido na Tabela 4, está incluso na equação para que a empresa tenha a noção da realidade sobre a sua ocupação.

\begin{tabular}{|c|c|c|c|c|c|}
\hline $\begin{array}{c}\text { Centro de } \\
\text { trabalho }\end{array}$ & $\begin{array}{c}\text { Demanda } \\
\text { (A) }\end{array}$ & $\begin{array}{l}\text { Fator } \\
\text { capac. }\end{array}$ & $\begin{array}{l}\text { Eficiência } \\
(\%)\end{array}$ & $\begin{array}{l}\text { Capac. real } \\
\text { necessária } \\
\text { (B) }\end{array}$ & $\begin{array}{c}\% \\
\text { Incremento } \\
\text { (B/A) }\end{array}$ \\
\hline Inserção A & 250 & 0,25 & 80 & 313 & 1,25 \\
\hline Inserção B & 750 & 0,751 & 66 & 1138 & 1,52 \\
\hline Almoxarifado & 1000 & 0,978 & 90 & 1087 & 1,09 \\
\hline Pré-montagem & 1000 & 0,988 & 85 & 1162 & 1,16 \\
\hline Estufa normal & 974 & 0,947 & 90 & 1052 & 1,08 \\
\hline Estufa especial & 26 & 0,025 & 90 & 28 & 1,07 \\
\hline Prensa & 1000 & 0,978 & 85 & 1150 & 1,15 \\
\hline Torno A & 700 & 0,675 & 85 & 794 & 1,13 \\
\hline Torno B & 300 & 0,289 & 85 & 340 & 1,13 \\
\hline Máquina Y & 60 & 0,058 & 90 & 65 & 1,07 \\
\hline $\begin{array}{c}\text { Montagem } \\
\text { especial }\end{array}$ & 150 & 0,159 & 80 & 199 & 1,33 \\
\hline Montagem & 1000 & 1,004 & 85 & 1181 & 1,18 \\
\hline Máquina laser & 1000 & 0,963 & 90 & 1070 & 1,07 \\
\hline Pintura & 100 & 0,096 & 85 & 113 & 1,13 \\
\hline
\end{tabular}

Tabela 4. Capacidade real necessária para cada centro de trabalho. 
Tabela 5. \% de ocupação em cada centro de trabalho.

\begin{tabular}{|c|c|c|c|c|c|c|}
\hline $\begin{array}{l}\text { Centro } \\
\text { trabalho }\end{array}$ & $\begin{array}{l}\text { Demanda } \\
\text { (D) }\end{array}$ & $\begin{array}{c}\text { Incremento } \\
(\%)\end{array}$ & $\begin{array}{l}\text { Tempo Padrão } \\
\text { (TPM) }\end{array}$ & $\begin{array}{l}\text { Horas disponiveis } \\
\text { (HD) }\end{array}$ & $\begin{array}{c}\mathrm{N}^{0} \text { de recursos } \\
\text { (NR) }\end{array}$ & $\begin{array}{c}\text { \% Ocupação } \\
\text { real }\end{array}$ \\
\hline Inserção A & 250 & 1,25 & 0,7142 & 17,6 & 19 & 67 \\
\hline Inserção B & 750 & 1,52 & 0,0714 & 17,6 & 5 & 92 \\
\hline Almoxarifado $^{1}$ & 1000 & 1,09 & 0,0019 & 17,6 & 1 & 12 \\
\hline Pré-montagem & 1000 & 1,16 & 0,0637 & 17,6 & 5 & 84 \\
\hline Estufa normal & 974 & 1,08 & 0,0419 & 17,6 & 4 & 63 \\
\hline Estufa especial & 26 & 1,07 & 0,3846 & 17,6 & 3 & 20 \\
\hline Prensa & 1000 & 1,15 & 0,0420 & 17,6 & 4 & 69 \\
\hline Torno A & 700 & 1,13 & 0,0464 & 17,6 & 3 & 69 \\
\hline Torno B & 300 & 1,13 & 0,0208 & 17,6 & 1 & 40 \\
\hline Máquina $Y$ & 60 & 1,07 & 0,1375 & 17,6 & 1 & 50 \\
\hline Montagem especial & 150 & 1,33 & 0,0677 & 17,6 & 1 & 77 \\
\hline Montagem & 1000 & 1,18 & 0,0417 & 17,6 & 3 & 93 \\
\hline Máquina laser & 1000 & 1,07 & 0,0042 & 17,6 & 1 & 25 \\
\hline Pintura & 100 & 1,13 & 0,3139 & 17,6 & 2 & 101 \\
\hline
\end{tabular}

'O Almoxarifado é responsável por produzir os cabos dos motores, sendo que cada um possui, em média, 6 cabos. A capacidade real necessária está mensurada em motores e o tempo padrão está em h/cabo. Portanto, para calcular a ocupação do Almoxarifado, é necessário multiplicar o número de motores pela quantidade de cabos que eles possuem em média.

Como se observa na Tabela 4, os percentuais de incremento variam muito de um centro para outro. Apenas para comparação, através de uma consulta aos gestores do processo da empresa pesquisada, obteve-se que o valor de incremento adotado como padrão para todos os centros de trabalho é 10\%. Conclui-se que adotar o mesmo percentual para toda a fábrica prejudica os processos menos eficientes, visto que mascara o percentual de ocupação e retarda possíveis investimentos necessários.

Um dos autores acompanhou in loco o processo produtivo no período de realização do artigo. Observou-se que os centros de trabalho inserção B, montagem e pintura apresentavam problemas no cumprimento da produção programada, gerando frequentes formações de filas de subitens e, consequentemente, inúmeros atrasos. A Tabela 5 apresenta os resultados da ocupação real para cada centro de trabalho. Estes valores percentuais indicam quão sobrecarregado está o recurso em relação à demanda. Por exemplo, no centro de trabalho pintura, 101\% de ocupação significa que a produção a ser realizada está acima da sua capacidade. Assim, as células produtivas com maior quantidade de produtos em atraso são as mesmas que apresentaram os maiores índices de ocupação, confirmando o que foi observado empiricamente.

Além disso, observa-se que vários centros produtivos estão acima de $80 \%$. Devido à variabilidade do processo (diversos tempos padrões) e da demanda (sazonalidade, situação econômica, etc.) é muito difícil determinar um percentual máximo do índice de ocupação para começar a investir. A empresa em estudo adota que, em geral, a partir de $90 \%$ de ocupação, deve-se capacitar o centro de trabalho.
Partindo deste pressuposto, os centros inserção B, montagem e pintura necessitam de uma análise econômica mais aprofundada por parte da empresa em razão dos percentuais de ocupação apresentados.

\section{Conclusão}

A crescente competitividade no mundo corporativo faz com que as políticas de investimento no processo produtivo sejam cada vez mais relevantes para o sucesso da empresa. Neste contexto, o percentual de ocupação apresentado neste artigo é uma medida essencial para avaliar a necessidade de novos investimentos na cadeia produtiva. Adicionalmente, o índice de capacidade real necessária revela o dimensionamento que cada célula produtiva precisa ter para obter a demanda do cliente no final do processo. Para calcular este parâmetro, alia-se o fator de capacidade à eficiência em cada centro. Além disso, utiliza-se a matriz de transição da cadeia de Markov para incluir a análise de refugos e retrabalhos no fator de capacidade. A inserção dos refugos e retrabalhos é um diferencial na análise de capacidade da empresa, pois eles consomem recursos produtivos e esta consideração normalmente é desprezada na maioria das companhias. A comparação entre a capacidade atual da empresa e a real necessária gera um incremento de capacidade que está incluso no percentual de ocupação.

Um exemplo de como esta metodologia pode ser empregada foi demonstrado em um estudo de caso. 0 resultado obtido indicou que o cálculo de capacidade utilizado pela companhia está subdimensionado em relação ao proposto. Isto aconteceu porque ineficiências, refugos e retrabalhos não são normalmente considerados neste dimensionamento. 
Conclui-se que a empresa necessita de investimentos em capacidade nos processos considerados gargalos da produção para atender à demanda do cliente final.

Os fatores apresentados neste artigo auxiliam na tomada de decisão sobre novos investimentos, fornecendo uma ferramenta bastante útil na identificação de áreas produtivas sobrecarregadas. Conhecendo-se os gargalos da produção, é possível minimizar seus efeitos através de uma política de investimentos adequada para cada caso. Como consequência, a probabilidade de que o produto seja feito no prazo e na quantidade determinada pelo cliente aumenta. De maneira geral, esse resultado consiste numa vantagem competitiva importante sobre outras empresas que possuem falhas na determinação da sua real capacidade produtiva.

\section{Referências}

AL-DARRAB, 1. A. Relationships between productivity, efficiency, utilization, and quality. Work Study,v. 49, n. 3, p. 97-103,2000. http://dx.doi.org/10.1108/00438020010318073

ALVES, R.; DELGAD0, C. Processos estocásticos. Portugal: Faculdade de Economia, Universidade do Porto, 1997. Notas de aula.

BORTOLOTTl, S. L. V. et al. Estudo de custos para uma microempresa de guardanapos de papel utilizando cadeias absorventes de Markov. In: SIMPÓSIO DE ENGENHARIA DE PRODUCÃO - SIMPEP, 14., 2007, Bauru, SP, Brasil. Anais...2007.

BRANCO, R. M.; COELHO, A. S. Cadeias absorventes de Markov no processo produtivo de filé congelado de pescada. Revista Synergismus scyentifica, v. 1, p. 646-657, 2006.

CLARKE, A. B.;DISNEY, R. L. Probabilidade e processos estocásticos. Rio de Janeiro: Livros Técnicos e Científicos, 1979.

ENSLEY, M. D.; CARR, J. C. Institutional isomorphism in venture capital investment decision making: industry characteristics and investment preferences. Social Science Research Network, 2006. Disponível em: <http://ssrn. com/abstract=876394>. Acesso em: 27 jul. 2009.

HOYOS, A. Processos estocásticos e previsão. In: SIMPÓSIO NACIONAL DE PROBABILIDADE E ESTATÍSTICA, 4., 1980, Rio de Janeiro. Anais... 1980.
KATO, A. K.; TAKAKl, E. Y.; SOUZA, G. C. Modelagem da capacidade produtiva através da aplicação da engenharia de métodos em uma empresa de beneficiamento de mármores e granitos. In: ENCONTRO NACIONAL DE ENGENHARIA DE PRODUČ̃̃ - ENEGEP, 23., 2003, Ouro Preto, MG, Brasil. Anais... 2003.

KATOK, E. Investment in production resource flexibility: an empirical investigation of methods for planning under uncertainty. Naval Research Logistics, v. 50, 2003. Disponível em: <http://ssrn.com/abstract=673423>. Acesso em: 15 jul. 2009.

LEAL, F. et al. Uma ferramenta de ensino para análise de tempos nas relações de trabalho. In: SIMPÓSIO DE ENGENHARIA DE PRODUÇÃO - SIMPEP, 12., 2005, Bauru, SP, Brasil. Anais...

LOPES, M. T. R. et al. Uma abordagem para o estudo de tempos considerando paradas técnicas e organizacionais: um estudo de caso. In: ENCONTRO NACIONAL DE ENGENHARIA DE PRODUÇÃO - ENEGEP, 23., 2003, Ouro Preto, MG, Brasil. Anais... 2003.

PAPOULIS, A. Probability, random variables, and sthocastic processes. Tokio: McGraw-Hill Kogakusha, 1965.

PEINADO, J.; GRAEML, A. R. Administração da produção: operações industriais e de serviços. Curitiba: UnicenP, 2007.

SALIM, R. Measuring productive capacity realization of Bangladesh food manufacturing: a random coefficient frontier approach. Social Science Research Network, 2001. Disponível em: <http://ssrn.com/abstract=1222402>. Acesso em: 27 jul. 2009.

SHAMBLIN, J. E.; STEVENS JUNIOR, G. T. Pesquisa operacional - Uma abordagem básica. São Paulo: Atlas, 1979.

SLACK, N.; CHAMBERS, S.; JOHNSTON, R. Administração da produção. 2. ed. São Paulo: Atlas, 2002.

TERRA, M. L. C. Cadeias de Markov. Bahia: Universidade Estadual de Santa Cruz, 2006. Monografia.

WATTS, T. et al. Structural limits of capacity and implications for visibility. Journal of Accounting \& Organizational Change, v. 5, n. 2, p. 294-312, 2009. http://dx.doi. org/10.1108/18325910910963472

\section{Agradecimentos}

Gostaríamos de agradecer aos referees pelas contribuições valiosas que aperfeiçoaram este trabalho. Também à empresa que disponibilizou os dados para o estudo de caso e ao CNPq pelo apoio financeiro.

\title{
Determination of necessary real capacity in productive process using Markov chain
}

\begin{abstract}
All developing companies must decide once in a while whether it is required to perform new investments to handle a growing demand. In order to make this decision, it is essential to know whether the current productive capacity is able to supply the new demand. However, just few companies realize that refuse and rework use production resources, which must be taken into account in the productive capacity calculation. The aim of this work was to include these factors in factory capacity analysis, using Markov chain stochastic transition matrix as a tool to obtain the capacity factor. This factor - used together with the efficiency index and the required demand in the end of the process - results in the necessary real capacity. A case study exemplifies the proposed methodology, presenting results that allow for the calculation of the real occupation index for each production cell. The calculation of this index demonstrated that some production cells presented more than $90 \%$ of occupation and needed investments in their productive capacity.
\end{abstract}

\section{Keywords}

Productive capacity. Stochastic process. Markov chain. Degree of capacity utilization. 